\title{
CrystEngComm
}

Check for updates

Cite this: CrystEngComm, 2017, 19, 2517

Received 19th February 2017

Accepted 1st April 2017

DOI: $10.1039 / c 7 c e 00346 c$

rsc.li/crystengcomm

\section{Diiodomethane as a halogen bond donor toward metal-bound halides $\uparrow$}

\author{
Alexander S. Novikov, (D) Daniil M. Ivanov, (D) \\ Margarita S. Avdontceva (D) and Vadim Yu. Kukushkin (D)
}

\begin{abstract}
A 1,3,5,7,9-pentaazanona-1,3,6,8-tetraenate (PANT) chloride platinum(॥) complex (1) was obtained via the metal-mediated double coupling of 2,3-diphenylmaleimidine with both nitrile ligands in trans$\left[\mathrm{PtCl}_{2}\left(\mathrm{NC}^{t} \mathrm{Bu}\right)_{2}\right]$. Compound 1 was then co-crystallized with diiodomethane forming solvate $1 \cdot \frac{1}{2} \mathrm{CH}_{2} \mathrm{I}_{2}$. The XRD experiment reveals that this solvate displays the halogen bonds $\mathrm{H}_{2} \mathrm{C}(\mathrm{I})-\mathrm{I} \cdots \mathrm{Cl}-\mathrm{Pt}$ and hydrogen bonds $\mathrm{I}_{2} \mathrm{C}(\mathrm{H})-\mathrm{H} \cdots \mathrm{Cl}-\mathrm{Pt}$, which join two complex and one $\mathrm{CH}_{2} \mathrm{I}_{2}$ molecules in a heterotrimeric supramolecular cluster. Inspection of the CCDC database reveals only one example of the halogen bond $\mathrm{H}_{2} \mathrm{C}(\mathrm{I})-\mathrm{\cdots}-\mathrm{I}-\mathrm{Pt}$ between the $\mathrm{CH}_{2} \mathrm{I}_{2}$ molecule and metal-coordinated halide in the structure of VEMWOA. In VEMWOA, $\mathrm{CH}_{2} \mathrm{I}_{2}$ serves solely as a halogen bond donor with no hydrogen bond contribution. Results of the Hirshfeld surface analysis and DFT calculations (M06/DZP-DKH level of theory) followed by topological analysis of the electron density distribution within the formalism of Bader's theory (QTAIM method) for both $1 \cdot \frac{1}{2} \mathrm{CH}_{2} \mathrm{I}_{2}$ and VEMWOA confirmed the formation of these weak interactions. The evaluated energies of halogen bonds involving $\mathrm{CH}_{2} \mathrm{l}_{2}$ are in the $2.2-2.8 \mathrm{kcal} \mathrm{mol}^{-1}$ range.
\end{abstract}

\section{Introduction}

Halogen bonding ${ }^{1}(\mathrm{XB})$ is one of the most actively studied types of weak interactions ${ }^{2-4}$ insofar as along with hydrogen bonding, metallophilic interactions, and $\pi$-stacking, XB is efficiently used as a tool in crystal engineering and in supramolecular organization. ${ }^{2,3,5}$ Recent applications of XB include stabilization of explosives ${ }^{6}$ and synthesis of systems with tunable photophysical properties. ${ }^{7}$ XBs also play important roles in organocatalysis ${ }^{8}$ and in the metabolism of biologically active halogen-containing compounds. ${ }^{9}$

In many reports devoted to $\mathrm{XB}$, iodine-based bifunctional $\mathrm{XB}$ donors such as 1,2- and 1,4-diiodoperfluorobenzenes were employed because of their availability, large $\sigma$-holes, and high solubility in most common organic solvents. ${ }^{2,10}$ However, more and more attention is now paid to halomethanes, which can also behave as polyfunctional XB donors. ${ }^{11-20}$ Concurrently, halide complexes of d-metals can be employed as $\mathrm{XB}$ acceptors and their combination with halomethanes leads to supramolecular clusters, chains, and 3D networks. ${ }^{17,18,20-22}$

Saint Petersburg State University, Universitetskaya Nab. 7/9, Saint Petersburg, 199034 Russian Federation. E-mail: v.kukushkin@spbu.ru

$\dagger$ Electronic supplementary information (ESI) available: Crystal data and structure refinement data. Cartesian atomic coordinates of model clusters. CCDC 1532142. For ESI and crystallographic data in CIF or other electronic format see DOI: $10.1039 / \mathrm{c} 7 \mathrm{ce} 00346 \mathrm{c}$
The halomethanes $\mathrm{CBr}_{4}{ }^{11-13,18-20} \quad \mathrm{CHI}_{3},{ }^{14,15,17,23}$ $\mathrm{CHBr}_{3},{ }^{11,12,20}$ and $\mathrm{CFBr}_{3}{ }^{12,19}$ are the most commonly used among other halomethanes in the formation of XBs with uncomplexed halides and polyhalometalate anions. Our recent works indicated that even weak $\mathrm{XB}$ donors such as $\mathrm{CHCl}_{3}, \mathrm{CH}_{2} \mathrm{Cl}_{2}$, and $\mathrm{CH}_{2} \mathrm{Br}_{2}$ (Fig. 1) are still able to form supramolecular clusters with chloride anions and chloride ligands in metal complexes held by XBs and $\mathrm{HBs}^{16,21,22}$ or by simultaneous XB and HB. ${ }^{16,21,22}$

In contrast to a rather broad application of halomethanes in crystal engineering, diiodomethane $\left(\mathrm{CH}_{2} \mathrm{I}_{2}\right)$ - despite its relatively large $\sigma$-holes (Fig. 1 ; positive potential is up to 23.1 kcal $\mathrm{mol}^{-1}$ on the 0.001 a.u. molecular surface) - was poorly studied $^{25-28}$ as an XB donor. Nassimbeni et al. reported a series of halomethane solvates of tetrakis(4-bromophenyl)- and

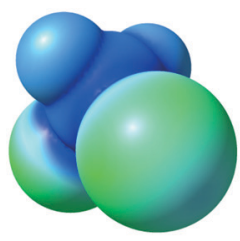

$\mathrm{CH}_{2} \mathrm{Cl}_{2}$

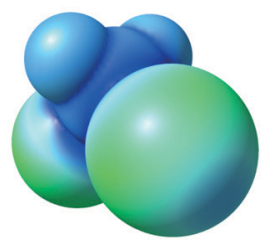

$\mathrm{CH}_{2} \mathrm{Br}_{2}$

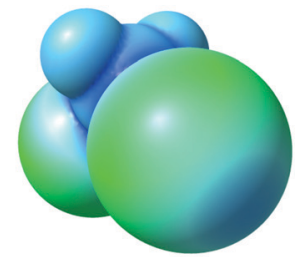

$\mathrm{CH}_{2} \mathrm{I}_{2}$
Fig. 1 ESP distribution in the $\mathrm{CH}_{2} \mathrm{X}_{2}(\mathrm{X}=\mathrm{Cl}, \mathrm{Br}, \mathrm{I})$ dihalomethane molecules (M06-2X/CEP-121G level of theory). ${ }^{24}$ Green color negative ESP, blue color - positive ESP. 
tetrakis(4-iodophenyl)ethylenes, where diiodomethane forms $\mathrm{H}_{2} \mathrm{C}(\mathrm{I})-\mathrm{I} \cdots \mathrm{Br}-\mathrm{C}$ and $\mathrm{H}_{2} \mathrm{C}(\mathrm{I})-\mathrm{I} \cdots \mathrm{I}-\mathrm{C}$ contacts assigned ${ }^{25}$ to $\mathrm{XB}$ after comparison of their geometrical parameters with the IUPAC geometrical criteria ${ }^{1}$ for XB. The other three reports ${ }^{25-28}$ were focused on crystalline $\mathrm{CH}_{2} \mathrm{I}_{2}$ exhibiting numerous $\mathrm{C}-\mathrm{I} \cdots \mathrm{I}-\mathrm{C}$ $\mathrm{XBs}$, where one diiodomethane molecule is an $\mathrm{XB}$ donor and another molecule behaves as an $\mathrm{XB}$ acceptor, again in full agreement with the IUPAC criteria. ${ }^{1}$ In addition, Geiser et al. ${ }^{29}$ observed weak $\mathrm{H}_{2} \mathrm{C}(\mathrm{I})-\mathrm{I} \cdots \mathrm{C}_{60}$ interactions by $\mathrm{XRD}$ in the crystals of $\mathrm{C}_{60} \cdot \mathrm{C}_{6} \mathrm{H}_{6} \cdot \mathrm{CH}_{2} \mathrm{I}_{2}$, but these contacts were not treated as XBs.

Upon our studies of $\mathrm{XB}$ between platinum chloride complexes and halomethanes, ${ }^{17,22}$ we found that $1,3,5,7,9-$ pentaazanona-1,3,6,8-tetraenate (PANT) chloride platinum(II) complex $^{30} 1$ (Fig. 2) co-crystallizes with diiodomethane forming solvate $1 \cdot \frac{1}{2} \mathrm{CH}_{2} \mathrm{I}_{2}$. The XRD experiment reveals that this solvate displays $\mathrm{H}_{2} \mathrm{C}(\mathrm{I})-\mathrm{I} \cdots \mathrm{Cl}-\mathrm{Pt} \mathrm{XBs}$ and $\mathrm{I}_{2} \mathrm{C}(\mathrm{H})-\mathrm{H} \cdots \mathrm{Cl}-$ Pt HBs, which join two complexes and one $\mathrm{CH}_{2} \mathrm{I}_{2}$ molecule in one heterotrimeric supramolecular cluster. The nature of these weak interactions was also studied theoretically and their energies were evaluated in the range from 2.2 to $2.5 \mathrm{kcal}$ mol ${ }^{-1}$ showing the ability of $\mathrm{CH}_{2} \mathrm{I}_{2}$ to behave as an $\mathrm{XB}$ donor. We also verified by theoretical calculations overlooked XBs associated with $\mathrm{CH}_{2} \mathrm{I}_{2}$ in the structure of VEMWOA (2.4-2.8 kcal $\mathrm{mol}^{-1}$ ). All these results are consistently disclosed in the sections that follow.

\section{Experimental}

\section{$\mathrm{X}$-ray structure determination}

A suitable crystal of $1 \cdot \frac{1}{2} \mathrm{CH}_{2} \mathrm{I}_{2}$ was studied using an Agilent Technologies Supernova Atlas diffractometer (monochromated MoK $\alpha$ radiation, $\lambda=0.71073 \AA$ ). The temperature was kept at $100 \mathrm{~K}$. The structure has been solved by direct methods and refined by means of the SHELXL- $97^{31}$ program incorporated in the OLEX2 program package ${ }^{32}$ using Least Squares minimization. The carbon-bound $\mathrm{H}$ atoms were placed in calculated positions and were included in the refinement in the 'riding' model approximation with $U_{\text {iso }}(\mathrm{H})$ set to $1.5 U_{\text {eq }}(\mathrm{C})$ and $\mathrm{C}-\mathrm{H}=0.96 \AA$ for the $\mathrm{CH}_{3}$ groups, $U_{\text {iso }}(\mathrm{H})$ set to $1.2 U_{\text {eq }}(\mathrm{C})$ and $\mathrm{C}-\mathrm{H}=0.93 \AA$ for the $\mathrm{CH}$ groups, and $U_{\text {iso }}(\mathrm{H})$ set to $1.2 U_{\text {eq }}(\mathrm{N})$ and $\mathrm{N}-\mathrm{H}=0.86 \AA$ for the $\mathrm{NH}$ groups. Empirical absorption correction was applied in the CrysAlisPro $^{33}$ program complex using spherical harmonics, implemented in the SCALE3 ABSPACK scaling algorithm.

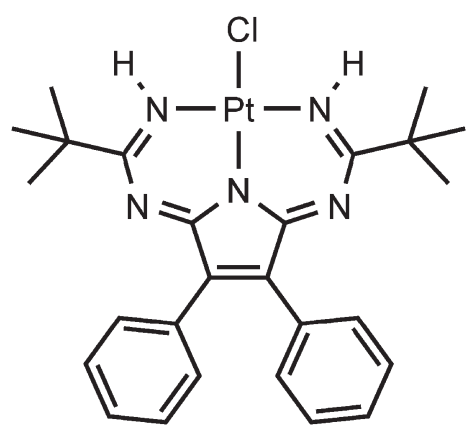

Fig. 2 Schematic representation of 1.
The crystallographic details are summarized in ESI $\dagger$ Table S2.

\section{Computational details}

Single point calculations based on the experimental X-ray geometry (quasi-solid-state approach) have been carried out at the DFT level of theory using the M06 functional ${ }^{34}$ (this functional was specifically developed to describe weak dispersion forces and non-covalent interactions) with the help of the Gaussian-09 $9^{35}$ program package. The Douglas-Kroll-Hess 2nd-order scalar relativistic calculations requesting a relativistic core Hamiltonian were carried out using DZP-DKH basis sets $^{36-40}$ for all atoms. The topological analysis of the electron density distribution with the help of the atoms-inmolecules (QTAIM) method developed by Bader ${ }^{41}$ has been performed by using the Multiwfn program (version 3.3.8). ${ }^{42}$

We used the Chemcraft program (version 1.8$)^{43}$ for visualization of electrostatic surface potential distribution. The Hirshfeld molecular surfaces were generated by the CrystalExplorer 3.1 program $^{44,45}$ based on the results of the X-ray study. The normalized contact distances, $d_{\text {norm }}{ }^{46}$ based on Bondi's van der Waals radii, ${ }^{47}$ were mapped into the Hirshfeld surfaces. In the color scale, negative values of $d_{\text {norm }}$ are visualized by the red color indicating contacts shorter than the sum of van der Waals radii. The white color denotes intermolecular distances close to van der Waals contacts with $d_{\text {norm }}$ equal to zero. In turn, contacts longer than the sum of van der Waals radii with positive $d_{\text {norm }}$ values are colored with blue. The Cartesian atomic coordinates of model clusters are presented in Tables S3 and S4 (ESI $\dagger$ ).

\section{Results and discussion}

General approach for verification of XB between organic and metal halides

Two types of short halogen $\cdots$ halogen contacts are commonly discussed in the literature (Fig. 3).

Type $\mathrm{I}$ is a packing-induced contact (which is actually not an $\mathrm{XB}$, see ref. 48), whereas type II is due to a classic XB because a halogen atom with a $90^{\circ}$ angle provides its lone pair for interaction and the other one provides its $\sigma$-hole (or, in other words, an area of electropositive potential). According to the IUPAC definition, ${ }^{1} \mathrm{XB}$ is the real $\mathrm{R}-\mathrm{X} \cdots \mathrm{Y}(\mathrm{X}=$ halogen $)$ contact, when, firstly, the interatomic distance between $\mathrm{X}$ and an appropriate Lewis base ( $\mathrm{Y}=\mathrm{F}, \mathrm{O}, \mathrm{N}, \mathrm{Cl}$, etc.) is less than the sum of their vdW radii and, secondly, the $\mathrm{R}-\mathrm{X} \cdots \mathrm{Y}$ angle is close to $180^{\circ}$; exceptions from the linearity have been reviewed by Rissanen. ${ }^{49}$

It is not surprising that metal halide species - when they are non-covalently linked to organic $\mathrm{R}-\mathrm{X}$ halogen bond donors - exhibit certain deviations from linearity of the $\mathrm{R}$ $\mathrm{X} \cdots \mathrm{X}-[\mathrm{M}]$ fragment. Fig. 4 schematically illustrates the difference in ESPs between organic- and metal-bound halides.

In contrast to conventional organic $\mathrm{XB}$ donors, $\mathrm{R}-\mathrm{X}$, the ESP of the complexed halides, as, e.g., calculated by Brammer and co-workers, ${ }^{50}$ is negative at both electron belt areas and 
Type I

(packing induced contact)
Type II

(classic XB)

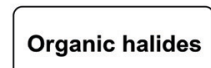

Metal halides
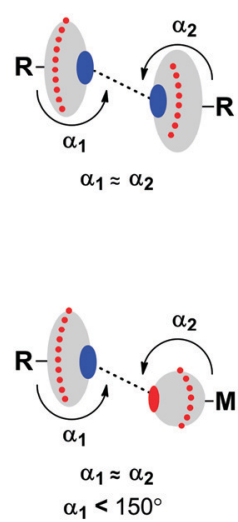
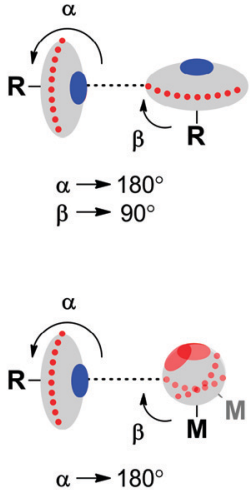

Second angle criterion is not fulfilled

Fig. 3 Illustration of the difference between carbon- (left) and metal-bound (right) halides.
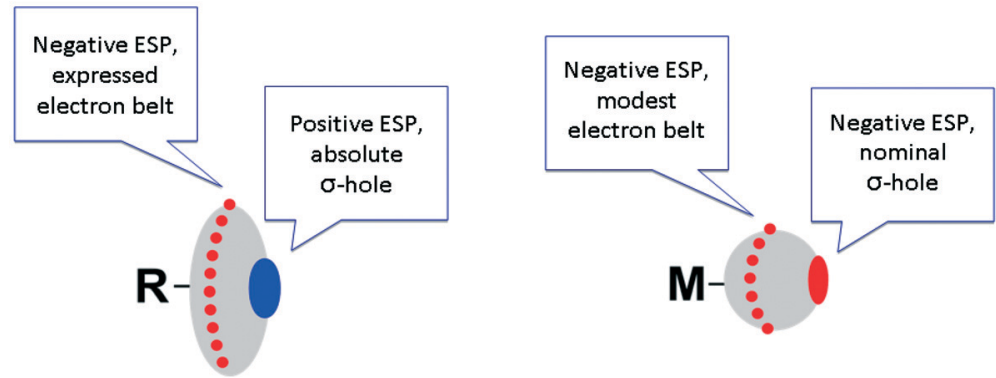

Fig. 4 Schematic representation of different ESP distributions on the halogen atoms in organic (left) and metal halides (right).

also at the so-called $\sigma$-hole. This $\sigma$-hole is only nominal and its formulation has only relative, but not absolute sense. As an additional illustration (Fig. 5), we calculated the ESPs $V_{\mathrm{S}}(\mathbf{r})$
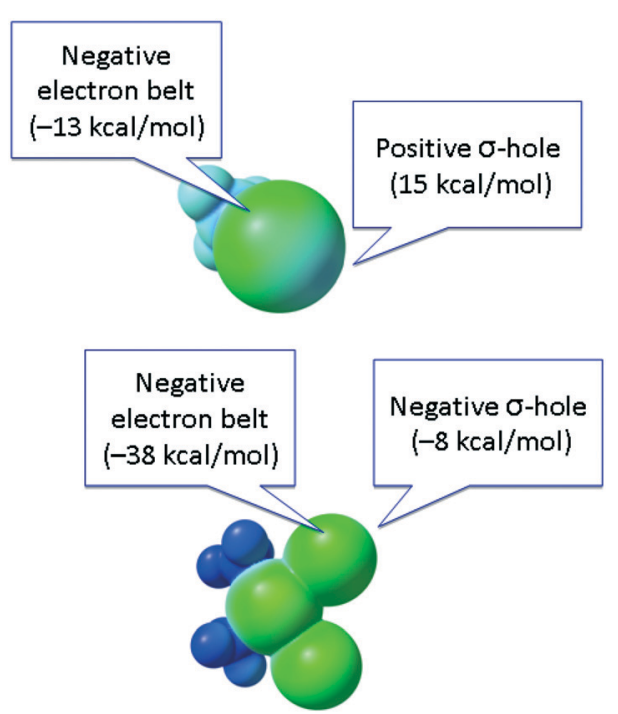

Fig. 5 ESP distribution in the $\mathrm{CH}_{3}$ l (top) and cis- $\left[\mathrm{PtI}_{2}\left(\mathrm{NH}_{3}\right)_{2}\right]$ (bottom) species. Green color - negative ESP, blue color - positive ESP. on the molecular vdW surfaces of $\mathrm{CH}_{3} \mathrm{I}$ and cis- $\left[\mathrm{PtI}_{2}\left(\mathrm{NH}_{3}\right)_{2}\right]$ taken as model systems (optimization in the gaseous phase at the M06/6-311++G** level of theory, quasi-relativistic Stuttgart pseudopotentials and appropriate contracted basis sets MWB60 and MWB46 were used on the platinum and iodine atoms, respectively).

It is clear that the organic halide has an expressed negative electron belt and deep positive $\sigma$-hole. In contrast, the ESP of the platinum-bound iodides is entirely negative, whereas the $\sigma$-hole is "positive" only relatively to the electron belt area rather than in its absolute value. Fig. 3 (bottom) illustrates the $\mathrm{R}-\mathrm{X} \cdots \mathrm{X}-[\mathrm{M}]$ bonding with particular emphasis on the possibility of deviation from linearity due to the flotation of $\mathrm{X}^{-}[\mathrm{M}]$ shown in Fig. 3 by the semitransparent species. Hence, the linearity of the $\mathrm{R}-\mathrm{X} \cdots \mathrm{X}-[\mathrm{M}]$ angle is not a univocal criterion for verification of the attractive $\mathrm{XB}$ interaction.

All these considerations point out to the need of certain theoretical calculations for reliable identification of noncovalent $\mathrm{R}-\mathrm{X} \cdots \mathrm{X}-[\mathrm{M}]$ interactions. In this work, we follow this approach for verification of XBs, viz. we applied the vdW IUPAC criterion for identification of possible halogen $\cdots$ halogen interactions, whereupon we conducted theoretical calculations irrespectively of the applicability of the angle IUPAC criterion. 
XRD structure of the diiodomethane solvate featuring mixed $\mathrm{XB} / \mathrm{HB}$ bonding

Complex 1 was prepared as previously reported ${ }^{30}$ via the metal-mediated coupling of two nitrile ligands in trans$\left[\mathrm{PtCl}_{2}\left(\mathrm{NC}^{t} \mathrm{Bu}\right)_{2}\right]$ and 2,3-diphenylmaleimidine. Crystals of 1 $\cdot \frac{1}{2} \mathrm{CH}_{2} \mathrm{I}_{2}$ were obtained by slow evaporation of a solution of 1 in $\mathrm{CH}_{2} \mathrm{I}_{2}$ in air at RT. The crystallographic data and processing parameters for $1 \cdot \frac{1}{2} \mathrm{CH}_{2} \mathrm{I}_{2}$ are listed in Table S2 (ESI $\dagger$ ); the plots for the structure and selected bond lengths can be found in Fig. 6 and Table 1, respectively.

Previously, we reported two solvates $1 \cdot 1 \frac{1}{4} \mathrm{CH}_{2} \mathrm{Cl}_{2}$ and 1 $\cdot 1 \frac{2}{5} \mathrm{CH}_{2} \mathrm{Br}_{2}$, which demonstrated close cell parameters and similar packing features. ${ }^{22}$ We found the same heterotetrameric clusters $(1)_{2} \cdot\left(\mathrm{CH}_{2} \mathrm{X}_{2}\right)_{2}(\mathrm{X}=\mathrm{Cl}, \mathrm{Br})$ held by two simultaneous $\mathrm{H}_{2} \mathrm{C}(\mathrm{X})-\mathrm{X} \cdots \mathrm{Cl}-\mathrm{Pt} \mathrm{XBs}$ and $\mathrm{X}_{2} \mathrm{C}(\mathrm{H})-\mathrm{H} \cdots \mathrm{I}-\mathrm{Pt}$ HBs. These two clusters demonstrate the isostructural $\mathrm{CH}_{2} \mathrm{Cl}_{2} / \mathrm{CH}_{2} \mathrm{Br}_{2}$ exchange. Therefore, the next logical step was an attempt to use diiodomethane as a solvent and either an $\mathrm{XB}$ or a mixed $\mathrm{XB} /$ HB donor. The $\mathrm{CH}_{2} \mathrm{I}_{2}$ solvate, $1 \cdot \frac{1}{2} \mathrm{CH}_{2} \mathrm{I}_{2}$, however, exhibits another packing type different from those of $1 \cdot 1 \frac{1}{4} \mathrm{CH}_{2} \mathrm{Cl}_{2}$ and $\mathbf{1}$ $\cdot 1_{5}^{2} \mathrm{CH}_{2} \mathrm{Br}_{2}$, but some similarities with the dichloromethane and dibromomethane solvates can be detected even in this case (for details, see Fig. S1 in the ESI $\dagger$ ).

In $1 \cdot \frac{1}{2} \mathrm{CH}_{2} \mathrm{I}_{2}$, isolated heterotrimeric clusters $(\mathbf{1})_{2} \cdot\left(\mathrm{CH}_{2} \mathrm{I}_{2}\right)$ (Fig. 6) are formed from two complex molecules and one solvent molecule linked together by the $\mathrm{H}_{2} \mathrm{C}(\mathrm{I})-\mathrm{I} \cdots \mathrm{Cl}-\mathrm{Pt} \mathrm{XB}$ and $\mathrm{I}_{2} \mathrm{C}(\mathrm{H})-\mathrm{H} \cdots \mathrm{Cl}-\mathrm{Pt} \mathrm{HB}$. The corresponding parameters of both types of weak interactions are in accordance with the IUPAC definitions for $\mathrm{XB}^{1}$ and $\mathrm{HB} .^{51}$ The $\mathrm{I} 1 \mathrm{~S} \cdots \mathrm{Cl} 1 \mathrm{~A}$ distance is less than Rowland's ${ }^{52} R_{\mathrm{vdw}}(\mathrm{I})+R_{\mathrm{vdw}}(\mathrm{Cl})$ sum [3.4071(12) vs. 3.79 $\AA]$. The $\angle(\mathrm{C} 1 \mathrm{~S}-\mathrm{I} 1 \mathrm{~S} \cdots \mathrm{Cl} 1 \mathrm{~A})$ angle $\left[173.11(13)^{\circ}\right]$ is close to $180^{\circ}$, whereas the $\angle(\mathrm{I} 1 \mathrm{~S} \cdots \mathrm{Cl} 1 \mathrm{~A}-\mathrm{Pt} 1 \mathrm{~A})$ angle $\left[108.83(4)^{\circ}\right]$ is around $90^{\circ}$. All these mean that this interaction can be assigned to type II halogen $\cdots$ halogen contact, which is specific for $\mathrm{XB}^{51}$ Theoretical calculations given in the next section fully supported our XRD-based conclusions.

The H1SA $\cdots$ Cl1 distance is less than the corresponding vdW sum (2.622 vs. $2.86 \AA$ ), and the $\angle$ (C1S-H1SA $\cdots$ Cl1) angle $\left(157.5^{\circ}\right)$ is larger than $120^{\circ}$. The $\mathrm{C} 1 \mathrm{~S} \cdots \mathrm{Cl} 1$ separation is close to the corresponding vdW sum [3.538(5) vs. $3.53 \AA$ ㅇ] indicating that this HB should be treated as rather weak.
Table 1 Selected bond lengths in two independent molecules of 1 (Fig. 6)

\begin{tabular}{lclll}
\hline \multicolumn{2}{l}{ Molecule with Pt1 (left) } & & \multicolumn{2}{l}{ Molecule with Pt1A (right) } \\
\cline { 5 - 5 } Bond & Length, A & & Bond & Length, A \\
\hline Pt1-Cl1 & $2.3232(11)$ & & Pt1A-Cl1A & $2.3374(11)$ \\
Pt1-N1 & $1.967(4)$ & & Pt1A-N1A & $1.966(3)$ \\
Pt1-N3 & $1.948(3)$ & & Pt1A-N3A & $1.948(4)$ \\
Pt1-N5 & $1.969(4)$ & & Pt1A-N5A & $1.968(4)$ \\
N1-C1 & $1.303(5)$ & & N1A-C1A & $1.304(6)$ \\
C1-N2 & $1.371(6)$ & & C1A-N2A & $1.357(6)$ \\
N2-C2 & $1.300(6)$ & & N2A-C2A & $1.309(5)$ \\
C2-N3 & $1.360(5)$ & & C2A-N3A & $1.366(6)$ \\
N3-C3 & $1.361(6)$ & & N3A-C3A & $1.365(5)$ \\
C3-N4 & $1.312(6)$ & & C3A-N4A & $1.303(6)$ \\
N4-C4 & $1.384(5)$ & N4A-C4A & $1.366(6)$ \\
C4-N5 & $1.283(6)$ & C4A-N5A & $1.306(6)$
\end{tabular}

Two crystallographically independent molecules of $\mathbf{1}$ are almost the same (Table 1), and all the Pt-N bonds [1.948(4)$1.969(4) \AA]$ as well as the $\mathrm{C}-\mathrm{N}[1.357(6)-1.384(5) \AA]$ and $\mathrm{C}=\mathrm{N}$ $[1.283(6)-1.312(6) \AA]$ bonds in the PANT ligand are equal within $3 \sigma$. However, the Pt1A-Cl1A bond [2.3374(11) $\AA$ ] in the halogen-bonded molecule is slightly longer than the Pt1-Cl1 distance $[2.3232(11) \AA]$ in the hydrogen-bonded molecule.

This difference can be explained by more effective electron density redistribution caused by XB than that caused by $\mathrm{HB}$ (Fig. 7). The same elongation on the $\mathrm{Pt}-\mathrm{Cl}$ bonds was found in the previously reported trans- $\left[\mathrm{PtCl}_{2}\left(\mathrm{NCNR}_{2}\right)_{2}\right]$ complexes linked with iodoform as an $\mathrm{XB}$ donor via $\mathrm{C}-\mathrm{I} \cdots \mathrm{Cl}-\mathrm{Pt}$ XBs. ${ }^{17}$

\section{Halogen bond in the structure of VEMWOA}

Although until now no XBs between diiodomethane and metal halide complexes have been reported, our inspection of the CCDC database verified the $\mathrm{H}_{2} \mathrm{C}(\mathrm{I})-\mathrm{I} \cdots \mathrm{I}-\mathrm{Pt}$ XBs in the structure of VEMWOA, ${ }^{53}$ which represents the platinum(II) associate $\quad\left[\mathrm{PtI}_{2}\left\{S, S-\underline{\mathrm{P}}(\mathrm{Ph})_{2} \mathrm{CH}(\mathrm{Me}) \mathrm{CH}_{2} \mathrm{CH}(\mathrm{Me}) \mathrm{PPh}_{2}\right\}\right] \cdot \frac{1}{3} \mathrm{MeCN}$ $\cdot \frac{1}{3} \mathrm{CH}_{2} \mathrm{I}_{2}\left(2 \cdot \frac{1}{3} \mathrm{MeCN} \cdot \frac{1}{3} \mathrm{CH}_{2} \mathrm{I}_{2}\right)$ (Fig. 8).

In the corresponding work, ${ }^{53}$ it was pointed out that no anomalous van der Waals contacts were observed in $2 \cdot \frac{1}{3} \mathrm{MeCN}$ $\cdot \frac{1}{3} \mathrm{CH}_{2} \mathrm{I}_{2}$. By contrast, our inspection of this structure allows

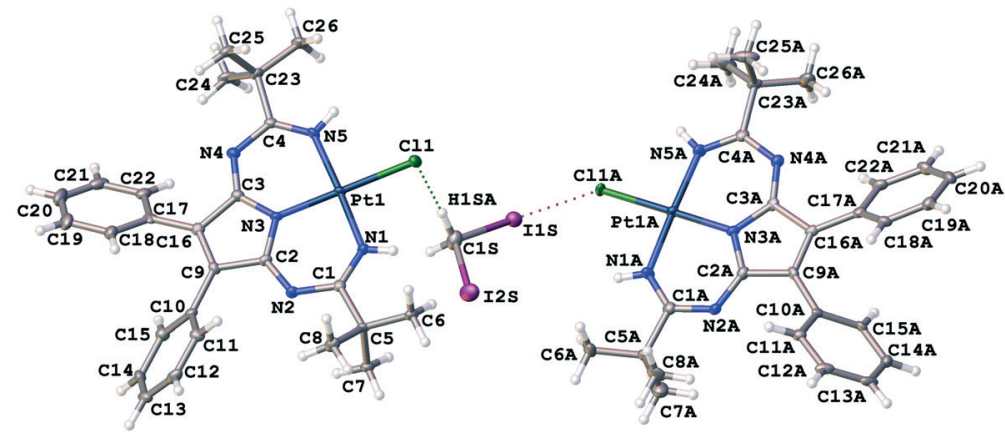

Fig. 6 View of heterotrimeric cluster $(1)_{2} \cdot \mathrm{CH}_{2} \mathrm{I}_{2}$ in $1 \cdot \frac{1}{2} \mathrm{CH}_{2} \mathrm{I}_{2}$ with the atomic numbering scheme. The $\mathrm{H}_{2} \mathrm{C}(\mathrm{I})-\mathrm{I} \cdots \mathrm{Cl}-\mathrm{Pt} \mathrm{XB}$ and $\mathrm{I}_{2} \mathrm{C}(\mathrm{H})-\mathrm{H} \cdots \mathrm{I}-\mathrm{Pt} \mathrm{HB}$ are shown by dotted lines. Hereinafter, thermal ellipsoids are drawn with $50 \%$ probability. 
<smiles>IC1CCCC[IH]C1I</smiles>

$[\mathrm{Pt}]$

Fig. 7 The XB effect on the Pt-Cl bond length.

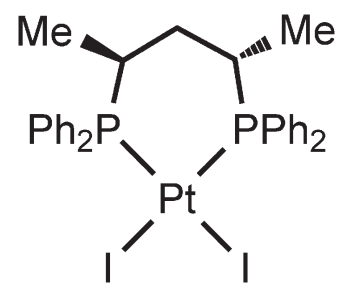

Fig. 8 Graphical representation of the complex in $2 \cdot \frac{1}{3} \mathrm{MeCN} \cdot \frac{1}{3} \mathrm{CH}_{2} \mathrm{I}_{2}$.

the identification of at least two $\mathrm{H}_{2} \mathrm{C}(\mathrm{I})-\mathrm{I} \cdots \mathrm{I}-\mathrm{Pt}$ short contacts (Fig. 9; $d(\mathrm{I} 8 \cdots \mathrm{I} 6)=3.5865(11) \AA, d(\mathrm{I} 7 \cdots \mathrm{I} 2)=3.6501(12) \AA)$, which are substantially less than the vdW $\operatorname{sum}^{52}\left(2 R_{\mathrm{vdW}}(\mathrm{I})=\right.$ $4.06 \AA$ ).

The I8 $\cdots$ I6 contact should be treated as a type II interhalogen interaction. ${ }^{48}$ This can be attributed to the typical $\mathrm{XB}$ because the angle values around these atoms $\left[159.0(4)^{\circ}\right.$ around I8 and $136.24(3)^{\circ}$ around I6] fulfill the IUPAC criteria ${ }^{1}$ and the difference between these two angles is more than $20^{\circ}$. However, the type of the second $17 \cdots \mathrm{I} 2$ contact is not clear. The very similar angle values around the iodine atoms $\left[153.2(4)^{\circ}\right.$ around I7 and $144.56(3)^{\circ}$ around I2] led to the idea that this contact could be assigned to type I halogen $\cdots$ halogen contact caused by the crystal packing. We decided to clarify the nature of the I7 $\cdots$ I 2 contact by ESP distribution at 2, calculated and analyzed at the M06/DZP-DKH level of theory in the Multiwfn program. ${ }^{42}$ In 2, the surface maxima with the negative absolute value of $V_{\mathrm{S}}(\mathbf{r})_{\max }(-18 \mathrm{kcal}$ $\mathrm{mol}^{-1}$ ) corresponding to "nominal $\sigma$-holes" (see above) were found on the iodine ligands (Fig. 10). The value of the I $\cdots I-$ Pt angle is acceptable for treatment of the iodide ligand as the nucleophilic partner in the non-covalent interaction. Taking into account the $\sigma$-hole on the diiodomethane I atom (Fig. 10, $23.1 \mathrm{kcal} \mathrm{mol}^{-1}$ ), the $\mathrm{C}-\mathrm{I} \cdots \mathrm{I}-\mathrm{Pt}$ contact also belongs to $\mathrm{XB}$ in agreement with the IUPAC definition. ${ }^{1}$

\section{Theoretical consideration of XB in the diiodomethane solvates}

The $\mathrm{H}_{2} \mathrm{C}(\mathrm{I})-\mathrm{I} \cdots \mathrm{Cl}-\mathrm{Pt} \mathrm{XB}$ and $\mathrm{I}_{2} \mathrm{C}(\mathrm{H})-\mathrm{H} \cdots \mathrm{Cl}-\mathrm{Pt} \mathrm{HB}$ were found in the crystal structure of $1 \cdot \frac{1}{2} \mathrm{CH}_{2} \mathrm{I}_{2}$ through the single-crystal XRD experiment. As always in such cases, in addition to the structural analysis, a detailed computational study directed toward understanding the nature of these non-covalent interactions is desirable. This study is particularly important when metal-bound halides are involved in XB (see above).

In order to confirm or deny the hypothesis on the existence of these weak contacts in the solid state and to quantify their energies from a theoretical viewpoint, we carried out DFT calculations and performed topological analysis of the

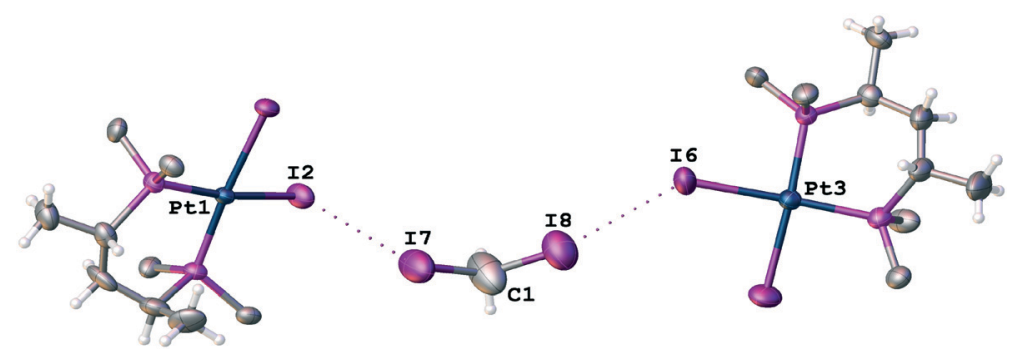

Fig. 9 View of the $\mathrm{H}_{2} \mathrm{C}(\mathrm{I})-\mathrm{l} \cdots \mathrm{l}-\mathrm{Pt}$ short contacts in VEMWOA. Phenyl rings are omitted for clarity.
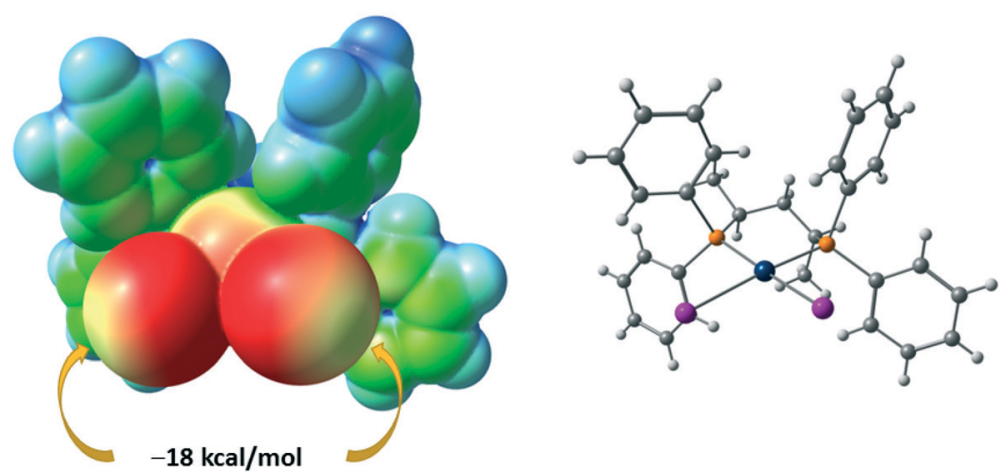

Fig. 10 ESP distribution in 2 from the structure VEMWOA. Red color - negative ESP, blue color - positive ESP. 
electron density distribution within the formalism of Bader's theory (QTAIM method) ${ }^{54}$ for the $(1)_{2} \cdot\left(\mathrm{CH}_{2} \mathrm{I}_{2}\right)$ heterotrimeric cluster as a model system (Table 2). This approach has already been successfully used by our group in studies of different non-covalent interactions (e.g., hydrogen, halogen and chalcogen bonding, metallophilic interactions, stacking) and properties of coordination bonds in various transition metal complexes. ${ }^{17,22,55-61}$ The contour line diagrams of the Laplacian distribution $\nabla^{2} \rho(\mathbf{r})$, bond paths, and selected zeroflux surfaces for intermolecular $\mathrm{H} \cdots \mathrm{Cl} \mathrm{HBs}$ and $\mathrm{I} \cdots \mathrm{Cl} \mathrm{XBs}$ are shown in Fig. 11. To visualize the studied non-covalent interactions, reduced density gradient (RDG) analysis ${ }^{62}$ was carried out, and RDG isosurfaces were plotted (Fig. 11).

The same procedure was performed for cluster $(2)_{2} \cdot\left(\mathrm{CH}_{2} \mathrm{I}_{2}\right)$ from VEMWOA to study the intermolecular XBs in this system (Table S1, Fig. S2†).

The QTAIM analysis demonstrates the presence of appropriate bond critical points (BCPs; $3,-1)$ for the intermolecular $\mathrm{H} \cdots \mathrm{Cl}$ HBs and $\mathrm{I} \cdots \mathrm{Cl}$ XBs in $(1)_{2} \cdot\left(\mathrm{CH}_{2} \mathrm{I}_{2}\right)$ and the $\mathrm{I} \cdots \mathrm{I}$ XBs in $(2)_{2} \cdot\left(\mathrm{CH}_{2} \mathrm{I}_{2}\right)$. The low magnitude of the electron density (0.011-0.013 Hartrees), positive values of the Laplacian (0.037-0.041 Hartrees), and close-to-zero positive energy density (0.001 Hartrees) in these BCPs are typical for both $\mathrm{HB}$ and XB. ${ }^{17,22,65,66}$ We have defined energies for these contacts according to the procedures proposed by Espinosa $e t$ al. ${ }^{63}$ and Vener et $a{ }^{64}{ }^{64}$ (Tables 2 and $\mathrm{S} 1 \dagger$ ) and one can state that the strength of these non-covalent interactions $(2.2-2.8 \mathrm{kcal}$ $\mathrm{mol}^{-1}$ ) is comparable with those of weak hydrogen bonds following the classification of Jeffrey ("strong": 40-15 kcal mol ${ }^{-1}$, "moderate": 15-4 kcal moll ${ }^{-1}$, "weak": $\left.<4 \mathrm{kcal} \mathrm{mol}^{-1}\right) .{ }^{67}$ The balance between the Lagrangian kinetic energy $G(\mathbf{r})$ and potential energy density $V(\mathbf{r})$ at the $\operatorname{BCPs}(3,-1)$ reveals the nature of these interactions. If the ratio $-G(\mathbf{r}) / V(\mathbf{r})>1$ is satisfied, then the nature of the appropriate interaction is purely non-covalent, whereas in the case of $-G(\mathbf{r}) / V(\mathbf{r})<1$, some covalent component takes place. ${ }^{68}$ Based on this criterion, we came to the conclusion that the covalent contribution is absent for intermolecular $\mathrm{H} \cdots \mathrm{Cl}$ HBs and $\mathrm{I} \cdots \mathrm{Cl}$ XBs in (1) $\cdot\left(\mathrm{CH}_{2} \mathrm{I}_{2}\right)$ and $\mathrm{I} \cdots \mathrm{I}$ XBs in $(2)_{2} \cdot\left(\mathrm{CH}_{2} \mathrm{I}_{2}\right)$. We additionally evaluated the magnitude of intermolecular interaction energies for HBs and $\mathrm{XBs}$ in $(1)_{2} \cdot\left(\mathrm{CH}_{2} \mathrm{I}_{2}\right)$ and $(2)_{2} \cdot\left(\mathrm{CH}_{2} \mathrm{I}_{2}\right)$ by the supermolecule method $\left(E_{\mathrm{int}}=E_{\mathrm{AB}}-E_{\mathrm{A}}-E_{\mathrm{B}}\right.$, i.e. the total electronic energy of the complex subtracting the energies of the monomers) using the crystallographic coordinates. The obtained values of intermolecular interaction energies $\left(E_{\text {int }}(\mathrm{H} \cdots \mathrm{Cl})=6.7\right.$ kcal mol ${ }^{-1}, E_{\text {int }}(\mathrm{I} \cdots \mathrm{Cl})=5.9 \mathrm{kcal} \mathrm{mol}^{-1}, E_{\text {int }}(\mathrm{I} \cdots \mathrm{I})=2.1-3.6 \mathrm{kcal}$ $\mathrm{mol}^{-1}$ ) are higher than (for $(\mathbf{1})_{2} \cdot\left(\mathrm{CH}_{2} \mathrm{I}_{2}\right)$ ) or comparable to (for (2) $\left.2 \cdot\left(\mathrm{CH}_{2} \mathrm{I}_{2}\right)\right)$ those from QTAIM analysis. Thus, the QTAIM

Table 2 Values of the density of all electrons $-\rho(\mathbf{r})$, Laplacian of electron density $-\nabla^{2} \rho(\mathbf{r})$, energy density $-H_{\mathrm{b}}$, potential energy density $-V(\mathbf{r})$, and Lagrangian kinetic energy $-G(r)$ (Hartree) at the bond critical points $(3,-1)$, corresponding to intermolecular $\mathrm{H} \cdots \mathrm{Cl} H B s$ and $\mathrm{I} \cdots \mathrm{Cl} \mathrm{XBs}$ in $(1)_{2} \cdot\left(\mathrm{CH}_{2} \mathrm{I}_{2}\right)$, bond lengths $-l(\AA)$, as well as energies for these contacts $E_{\text {int }}\left(\mathrm{kcal} \mathrm{mol}^{-1}\right)$, defined by two approaches

\begin{tabular}{lllllllll}
\hline Contact & $\rho(\mathbf{r})$ & $\nabla^{2} \rho(\mathbf{r})$ & $H_{\mathrm{b}}$ & $V(\mathbf{r})$ & $G(\mathbf{r})$ & $E_{\text {int }}{ }^{a}$ & $E_{\text {int }}^{b}$ \\
\hline $\mathrm{H} \cdots \mathrm{Cl}$ & 0.011 & 0.037 & 0.001 & -0.007 & 0.008 & 2.2 & 2.2 \\
$\mathrm{I} \cdots \mathrm{Cl}$ & 0.012 & 0.038 & 0.001 & -0.008 & 0.009 & 2.5 & 2.4
\end{tabular}

${ }^{a} E_{\text {int }}=-V(\mathbf{r}) / 2 .{ }^{63 b} E_{\text {int }}=0.429 G(\mathbf{r}) .{ }^{64}$
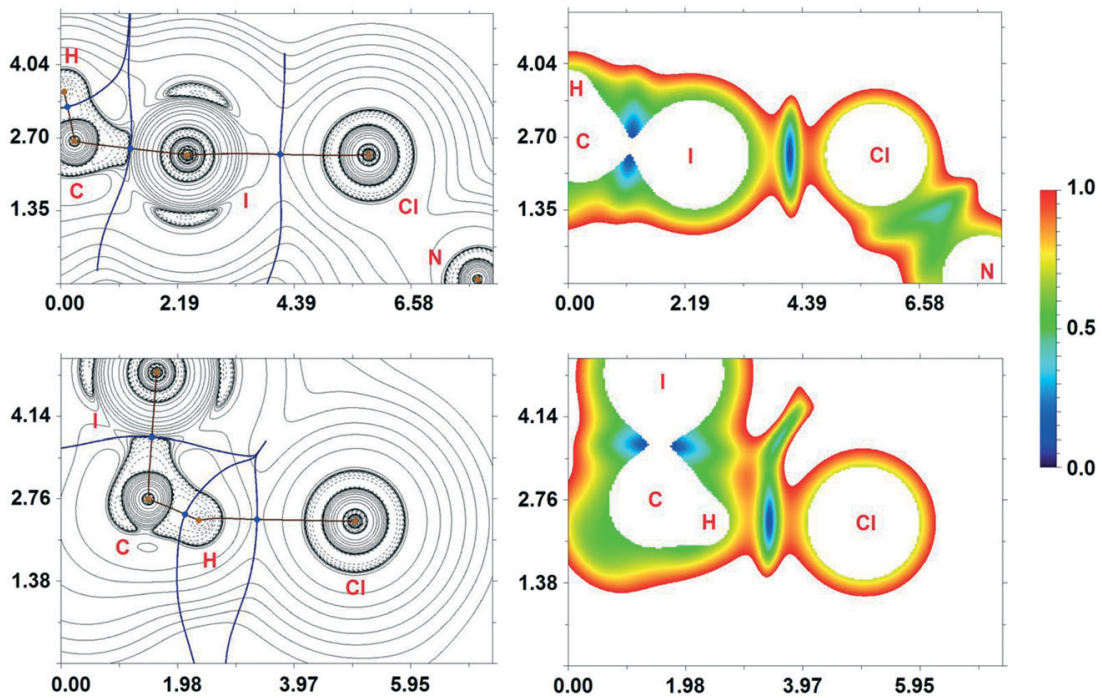

Fig. 11 Contour line diagrams of the Laplacian distribution $\nabla^{2} \rho(\mathbf{r})$, bond paths and selected zero-flux surfaces (left) and RDG isosurfaces referring to the non-covalent interactions (right) for the intermolecular $\mathrm{H} \cdots \mathrm{Cl} \mathrm{HBs}$ and $\mathrm{I} \cdots \mathrm{Cl} \mathrm{XBs}$ in $(1)_{2} \cdot\left(\mathrm{CH}_{2} \mathrm{I}_{2}\right)$. Bond critical points $(3,-1)$ are shown in blue, while nuclear critical points $(3,-3)$ are shown in pale brown. Length units $-\AA$, RDG isosurface values are given in Hartree. 


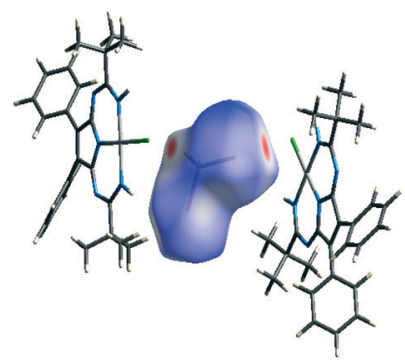

A

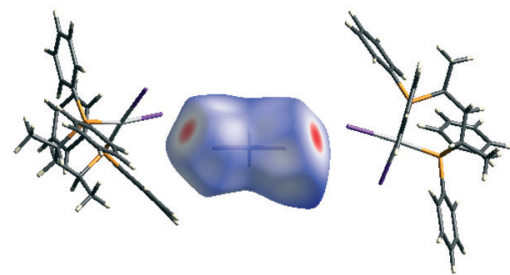

B

Fig. 12 The Hirshfeld surfaces of the $\mathrm{CH}_{2} \mathrm{I}_{2}$ molecule in the solvates $(1)_{2} \cdot\left(\mathrm{CH}_{2} \mathrm{I}_{2}\right)(\mathrm{A})$ and VEMWOA (B) with the colored scale, which corresponds to values ranging from $-0.2 \AA$ (red) to $1.5 \AA$ (blue).

approach gives underestimated values of interaction energies for electrostatically favored $\mathrm{HB}$ and $\mathrm{XB}$ interactions.

\section{Hirshfeld surface analysis of the crystal structures of $1 \cdot \frac{1}{2} \mathrm{CH}_{2} \mathbf{I}_{2}$ and VEMWOA}

The molecular Hirshfeld surface represents an area where molecules come into contact and its analysis gives the possibility of an additional insight into the nature of intermolecular interactions in the crystal state. For visualization, we have used a mapping of the normalized contact distance $\left(d_{\text {norm }}\right)$; its negative value enables identification of molecular regions of substantial importance for detection of short contacts.

Fig. 12A depicts the Hirshfeld surface of the $\mathrm{CH}_{2} \mathrm{I}_{2}$ molecule in the solvate $(1)_{2} \cdot\left(\mathrm{CH}_{2} \mathrm{I}_{2}\right)$. In the Hirshfeld surface of $\mathrm{CH}_{2} \mathrm{I}_{2}$, the regions of intermolecular $\mathrm{H} \cdots \mathrm{Cl}$ and $\mathrm{I} \cdots \mathrm{Cl}$ contacts, visualized by large red circle areas, are seen near the hydrogen and iodine atoms, respectively. The following intermolecular contacts give the largest contributions to the Hirshfeld surface of $\mathrm{CH}_{2} \mathrm{I}_{2}$ in the solvate $(1)_{2} \cdot\left(\mathrm{CH}_{2} \mathrm{I}_{2}\right)$ : I-H $66.9 \%$, H-H 22.5\%, Cl-H 3.4\%, I-Cl 3.3\%, H-C 2.2\%; contributions of other intermolecular contacts are less than $1 \%$.

Fig. 12B depicts the Hirshfeld surface of the $\mathrm{CH}_{2} \mathrm{I}_{2}$ molecule in VEMWOA. In the Hirshfeld surface of $\mathrm{CH}_{2} \mathrm{I}_{2}$, the regions of intermolecular I $\cdots$ I contacts, visualized by large red circle areas, are seen near the iodine atoms. The following intermolecular contacts give the largest contributions to the Hirshfeld surface of $\mathrm{CH}_{2} \mathrm{I}_{2}: \mathrm{H}-\mathrm{I} 54.1 \%$, H-H 20.8\%, I-I 9.1\%, $\mathrm{C}-\mathrm{H}$ 7.9\%, C-I 6.4\%; contributions of other intermolecular contacts are less than $1 \%$.

The Hirshfeld surface fingerprint plots (Fig. S2 and S3†) were generated using $d_{\mathrm{i}}$ (distance from the surface to the nearest atom in the molecule itself) and $d_{\mathrm{e}}$ (distance from the surface to the nearest atom in another molecule) as a pair of coordinates for each individual surface spot resulting in two-dimensional histograms. A color gradient in the plots ranging from blue to red represents the proportional contribution of contact pairs in the global surface.

Thus, the Hirshfeld surface analyses of $1 \cdot \frac{1}{2} \mathrm{CH}_{2} \mathrm{I}_{2}$ and VEMWOA confirm that in the crystalline state $\mathrm{CH}_{2} \mathrm{I}_{2}$ behaves as an XB and $\mathrm{HB}$ donor.

\section{Concluding remarks}

In this work, we used multidisciplinary combined and complementary experimental and theoretical approaches that allow bypassing certain limitations of the XRD method in the studies of halogen bond systems. In particular, we succeeded in overcoming difficulties associated with the deviation from linearity of $\mathrm{R}-\mathrm{X} \cdots \mathrm{X}-[\mathrm{M}]$ linkage insofar as this deviation complicates the experimental identification of XBs in organic halide $\cdots$ metal-bound halide systems.

We found that a weak XB donor such as diiodomethane can still form a halogen bond with metal-bound halides and $\mathrm{CH}_{2} \mathrm{I}_{2}$ can serve as either an $\mathrm{XB}$ or a mixed XB/HB donor. All these non-covalent interactions in $1 \cdot \frac{1}{2} \mathrm{CH}_{2} \mathrm{I}_{2}$ and VEMWOA were confirmed by Hirshfeld surface analysis, and their nature was investigated by DFT calculations and topological analysis of the electron density distribution within the formalism of Bader's theory (QTAIM method). The evaluated en-

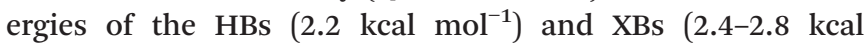
$\mathrm{mol}^{-1}$ ) again indicate their non-covalent character.

The results reported in this work can be used as a starting point for further studies of XBs in dihalomethane solutions, where they may be sufficiently strong to contribute, along with HBs, to the overall solvation. It is expected that all these findings can find an application in crystal engineering because they expand the arsenal of supramolecular organizations which may be useful for solvent storage ${ }^{69}$ or separation $^{70}$ and also in physical chemistry as they contribute to the understanding of solvation with halomethanes. We hope that our results open up an avenue to the generation of other diiodomethane associates and studies in this direction are underway in our group.

\section{Acknowledgements}

The experimental part of this work was conducted in the framework of the Russian Science Foundation project (14-1300060), whereas the theoretical part was performed under the Russian Foundation for Basic Research grant (16-33-00212). XRD studies were performed at the Center for X-ray Diffraction Studies of Saint Petersburg State University. The authors declare no competing financial interests. 


\section{References}

1 G. R. Desiraju, P. S. Ho, L. Kloo, A. C. Legon, R. Marquardt, P. Metrangolo, P. Politzer, G. Resnati and K. Rissanen, Pure Appl. Chem., 2013, 85, 1711-1713.

2 G. Cavallo, P. Metrangolo, R. Milani, T. Pilati, A. Priimagi, G. Resnati and G. Terraneo, Chem. Rev., 2016, 116, 2478-2601.

3 L. C. Gilday, S. W. Robinson, T. A. Barendt, M. J. Langton, B. R. Mullaney and P. D. Beer, Chem. Rev., 2015, 115, 7118-7195.

4 H. Wang, W. Z. Wang and W. J. Jin, Chem. Rev., 2016, 116, 5072-5104.

5 A. Mukherjee, S. Tothadi and G. R. Desiraju, Acc. Chem. Res., 2014, 47, 2514-2524.

6 K. B. Landenberger, O. Bolton and A. J. Matzger, J. Am. Chem. Soc., 2015, 137, 5074-5079.

7 V. V. Sivchik, A. I. Solomatina, Y.-T. Chen, A. J. Karttunen, S. P. Tunik, P.-T. Chou and I. O. Koshevoy, Angew. Chem., Int. Ed., 2015, 54, 14057-14060.

8 D. Bulfield and S. M. Huber, Chem. - Eur. J., 2016, 22, 14434-14450.

9 P. S. Ho, in Halogen Bonding I: Impact on Materials Chemistry and Life Sciences, Springer-Verlag Berlin, Berlin, 2014, pp. 241-276.

10 G. Cavallo, S. Biella, J. A. Lu, P. Metrangolo, T. Pilati, G. Resnati and G. Terraneo, J. Fluorine Chem., 2010, 131, 1165-1172.

11 S. V. Rosokha, I. S. Neretin, T. Y. Rosokha, J. Hecht and J. K. Kochi, Heteroat. Chem., 2006, 17, 449-459.

12 S. V. Rosokha, C. L. Stern and J. T. Ritzert, Chem. - Eur. J., 2013, 19, 8774-8788.

13 S. V. Lindeman, J. Hecht and J. K. Kochi, J. Am. Chem. Soc., 2003, 125, 11597-11606.

14 H. Bock and S. Holl, Z. Naturforsch., B: J. Chem. Sci., 2001, 56, 152-163.

15 H. G. Lohr, A. Engel, H. P. Josel, F. Vogtle, W. Schuh and H. Puff, J. Organomet. Chem., 1984, 49, 1621-1627.

16 P. V. Gushchin, G. L. Starova, M. Haukka, M. L. Kuznetsov, I. L. Eremenko and V. Y. Kukushkin, Cryst. Growth Des., 2010, 10, 4839-4846.

17 D. M. Ivanov, A. S. Novikov, I. V. Ananyev, Y. V. Kirina and V. Yu. Kukushkin, Chem. Commun., 2016, 52, 5565-5568.

18 S. V. Rosokha, J. Lu, T. Y. Rosokha and J. K. Kochi, Chem. Commun., 2007, 3383-3385.

19 S. V. Rosokha, C. L. Stern, A. Swartz and R. Stewart, Phys. Chem. Chem. Phys., 2014, 16, 12968-12979.

20 S. V. Rosokha and M. K. Vinakos, Cryst. Growth Des., 2012, 12, 4149-4156.

21 A. M. Afanasenko, M. S. Avdontceva, A. S. Novikov and T. G. Chulkova, Z. Kristallogr. - Cryst. Mater., 2016, 231, 435-440.

22 D. M. Ivanov, A. S. Novikov, G. L. Starova, M. Haukka and V. Y. Kukushkin, CrystEngComm, 2016, 18, 5278-5286.

23 W.-W. du Mont, V. Stenzel, J. Jeske, P. G. Jones, A. Sebald, S. Pohl, W. Saak and M. Baetcher, Inorg. Chem., 1994, 33, 1502-1505.
24 D. M. Ivanov, M. A. Kinzhalov, A. S. Novikov, I. V. Ananyev, A. A. Romanova, V. P. Boyarskiy, M. Haukka and V. Y. Kukushkin, Cryst. Growth Des., 2017, 17, 1353-1362.

25 F. M. A. Noa, S. A. Bourne and L. R. Nassimbeni, Cryst. Growth Des., 2015, 15, 3271-3279.

26 M. Podsiadlo and A. Katrusiak, CrystEngComm, 2008, 10, 1436-1442.

27 M. Podsiadlo, K. Dziubek, M. Szafranski and A. Katrusiak, Acta Crystallogr., Sect. B: Struct. Sci., 2006, 62, 1090-1098.

28 M. Podsiadlo and A. Katrusiak, J. Phys. Chem. B, 2008, 112, 5355-5362.

29 U. Geiser, S. K. Kumar, B. M. Savall, S. S. Harried, K. D. Carlson, P. R. Mobley, H. H. Wang, J. M. Williams, R. E. Botto, W. Liang and M. H. Whangbo, Chem. Mater., 1992, 4, 1077-1082.

30 D. M. Ivanov, P. V. Gushchin, A. S. Novikov, M. S. Avdontceva, A. A. Zolotarev, G. L. Starova, Y.-T. Chen, S.-H. Liu, P.-T. Chou and V. Yu. Kukushkin, Eur. J. Inorg. Chem., 2016, 2016, 1480-1487.

31 G. M. Sheldrick, Acta Crystallogr., Sect. A: Found. Crystallogr., 2008, 64, 112-122.

32 O. V. Dolomanov, L. J. Bourhis, R. J. Gildea, J. A. K. Howard and H. Puschmann, J. Appl. Crystallogr., 2009, 42, 339-341.

33 CrysAlisPro, Agilent Technologies Ltd., Version 1.171.136.120 (release 127-106-2012).

34 Y. Zhao and D. G. Truhlar, Theor. Chem. Acc., 2008, 120, 215-241.

35 M. J. Frisch, G. W. Trucks, H. B. Schlegel, G. E. Scuseria, M. A. Robb, J. R. Cheeseman, G. Scalmani, V. Barone, B. Mennucci, G. A. Petersson, H. Nakatsuji, M. Caricato, X. Li, H. P. Hratchian, A. F. Izmaylov, J. Bloino, G. Zheng, J. L. Sonnenberg, M. Hada, M. Ehara, K. Toyota, R. Fukuda, J. Hasegawa, M. Ishida, T. Nakajima, Y. Honda, O. Kitao, H. Nakai, T. Vreven, J. A. Montgomery, J. E. Peralta, F. Ogliaro, M. Bearpark, J. J. Heyd, E. Brothers, K. N. Kudin, V. N. Staroverov, T. Keith, R. Kobayashi, J. Normand, K. Raghavachari, A. Rendell, J. C. Burant, S. S. Iyengar, J. Tomasi, M. Cossi, N. Rega, J. M. Millam, M. Klene, J. E. Knox, J. B. Cross, V. Bakken, C. Adamo, J. Jaramillo, R. Gomperts, R. E. Stratmann, O. Yazyev, A. J. Austin, R. Cammi, C. Pomelli, J. W. Ochterski, R. L. Martin, K. Morokuma, V. G. Zakrzewski, G. A. Voth, P. Salvador, J. J. Dannenberg, S. Dapprich, A. D. Daniels, O. Farkas, J. B. Foresman, J. V. Ortiz, J. Cioslowski and D. J. Fox, in Gaussian 09, Revision C.01, Gaussian, Inc., Wallingford, CT, 2010.

36 C. L. Barros, P. J. P. de Oliveira, F. E. Jorge, A. C. Neto and M. Campos, Mol. Phys., 2010, 108, 1965-1972.

37 F. E. Jorge, A. C. Neto, G. G. Camiletti and S. F. Machado, J. Chem. Phys., 2009, 130, 6.

38 A. C. Neto and F. E. Jorge, Chem. Phys. Lett., 2013, 582, 158-162.

39 C. L. Barros, P. J. P. de Oliveira, F. E. Jorge, A. C. Neto and M. Campos, Mol. Phys., 2010, 108, 1965-1972.

40 R. C. de Berredo and F. E. Jorge, J. Mol. Struct.: THEOCHEM, 2010, 961, 107-112. 
41 R. F. W. Bader, Atoms in Molecules: A Quantum Theory, Oxford University Press, Oxford, 1990.

42 T. Lu and F. W. Chen, J. Comput. Chem., 2012, 33, 580-592.

43 http://www.chemcraftprog.com.

44 S. K. Wolff, D. J. Grimwood, J. J. McKinnon, M. J. Turner, D. Jayatilaka and M. A. Spackman, CrystalExplorer (Version 3.1), University of Western Australia, 2012.

45 M. A. Spackman and D. Jayatilaka, CrystEngComm, 2009, 11, 19-32.

46 J. J. McKinnon, D. Jayatilaka and M. A. Spackman, Chem. Commun., 2007, 3814-3816.

47 A. Bondi, J. Phys. Chem., 1964, 68, 441-451.

48 P. Metrangolo and G. Resnati, IUCrJ, 2014, 1, 5-7.

49 K. Rissanen, CrystEngComm, 2008, 10, 1107-1113.

50 L. Brammer, E. A. Bruton and P. Sherwood, Cryst. Growth Des., 2001, 1, 277-290.

51 E. Arunan, G. R. Desiraju, R. A. Klein, J. Sadlej, S. Scheiner, I. Alkorta, D. C. Clary, R. H. Crabtree, J. J. Dannenberg, P. Hobza, H. G. Kjaergaard, A. C. Legon, B. Mennucci and D. J. Nesbitt, Pure Appl. Chem., 2011, 83, 1637-1641.

52 R. S. Rowland and R. Taylor, J. Phys. Chem., 1996, 100, 7384-7391.

53 L. Jánosi, L. Kollár, P. Macchi and A. Sironi, J. Organomet. Chem., 2006, 691, 2846-2852.

54 R. F. W. Bader, Chem. Rev., 1991, 91, 893-928.

55 A. S. Novikov, M. L. Kuznetsov and A. J. L. Pombeiro, Chem. - Eur. J., 2013, 19, 2874-2888.

56 V. N. Mikhaylov, V. N. Sorokoumov, K. A. Korvinson, A. S. Novikov and I. A. Balova, Organometallics, 2016, 35, 1684-1697.

57 T. V. Serebryanskaya, A. S. Novikov, P. V. Gushchin, M. Haukka, R. E. Asfin, P. M. Tolstoy and V. Yu. Kukushkin, Phys. Chem. Chem. Phys., 2016, 18, 14104-14112.
58 E. Andrusenko, E. Kabin, A. S. Novikov, N. A. Bokach, G. L. Starova and V. Yu Kukushkin, New J. Chem., 2017, 41, 316-325.

59 X. Ding, M. J. Tuikka, P. Hirva, V. Yu. Kukushkin, A. S. Novikov and M. Haukka, CrystEngComm, 2016, 18, 1987-1995.

60 E. S. Yandanova, D. M. Ivanov, M. L. Kuznetsov, A. G. Starikov, G. L. Starova and V. Yu Kukushkin, Cryst. Growth Des., 2016, 16, 2979-2987.

61 A. S. Mikherdov, M. A. Kinzhalov, A. S. Novikov, V. P. Boyarskiy, I. A. Boyarskaya, D. V. Dar'in, G. L. Starova and V. Yu Kukushkin, J. Am. Chem. Soc., 2016, 138, 14129-14137.

62 E. R. Johnson, S. Keinan, P. Mori-Sánchez, J. ContrerasGarcía, A. J. Cohen and W. Yang, J. Am. Chem. Soc., 2010, 132, 6498-6506.

63 E. Espinosa, E. Molins and C. Lecomte, Chem. Phys. Lett., 1998, 285, 170-173.

64 M. V. Vener, A. N. Egorova, A. V. Churakov and V. G. Tsirelson, J. Comput. Chem., 2012, 33, 2303-2309.

65 I. Rozas, I. Alkorta and J. Elguero, J. Phys. Chem. A, 1998, 102, 9925-9932.

66 I. Rozas, I. Alkorta and J. Elguero, J. Am. Chem. Soc., 2000, 122, 11154-11161.

67 T. Steiner, Angew. Chem., Int. Ed., 2002, 41, 48-76.

68 E. Espinosa, I. Alkorta, J. Elguero and E. Molins, J. Chem. Phys., 2002, 117, 5529-5542.

69 C. B. Aakeröy, T. K. Wijethunga, J. Benton and J. Desper, Chem. Commun., 2015, 51, 2425-2428.

70 X. Q. Yan, Q. J. Shen, X. R. Zhao, H. Y. Gao, X. Pang and W. J. Jin, Anal. Chim. Acta, 2012, 753, 48-56. 